\title{
Non-HIV Pneumocystis pneumonia: do conventional community-acquired pneumonia guidelines under estimate its severity?
}

Nobuhiro Asai ${ }^{1 *}$, Shinji Motojima², Yoshihiro Ohkuni ${ }^{1}$, Ryo Matsunuma', Kei Nakasima', Takuya Iwasaki', Tamao Nakashita², Yoshihito Otsuka ${ }^{3}$ and Norihiro Kaneko ${ }^{1}$

\begin{abstract}
Background: Non-HIV Pneumocystis pneumonia (PCP) can occur in immunosuppressed patients having malignancy or on immunosuppressive agents. To classify severity, the A-DROP scale proposed by the Japanese Respiratory Society (JRS), the CURB-65 score of the British Respiratory Society (BTS) and the Pneumonia Severity Index (PSI) of the Infectious Diseases Society of America (IDSA) are widely used in patients with community-acquired pneumonia (CAP) in Japan. To evaluate how correctly these conventional prognostic guidelines for CAP reflect the severity of non-HIV PCP, we retrospectively analyzed 21 patients with non-HIV PCP.
\end{abstract}

Methods: A total of 21 patients were diagnosed by conventional staining and polymerase chain reaction (PCR) for respiratory samples with chest $x$-ray and computed tomography $(C T)$ findings. We compared the severity of 21 patients with PCP classified by A-DROP, CURB-65, and PSI. Also, patients' characteristics, clinical pictures, laboratory results at first visit or admission and intervals from diagnosis to start of specific-PCP therapy were evaluated in both survivor and non-survivor groups.

Results: Based on A-DROP, 18 patients were classified as mild or moderate; respiratory failure developed in 15 of these 18 (83.3\%), and 7/15 (46.7\%) died. Based on CURB-65, 19 patients were classified as mild or moderate; respiratory failure developed in 16/19 (84.2\%), and 8 of the 16 (50\%) died. In contrast, PSI classified 14 as severe or extremely severe; all of the 14 (100\%) developed respiratory failure and 8/14 (57.1\%) died. There were no significant differences in laboratory results in these groups. The time between the initial visit and diagnosis, and the time between the initial visit and starting of specific-PCP therapy were statistically shorter in the survivor group than in the non-survivor group.

Conclusions: Conventional prognostic guidelines for CAP could underestimate the severity of non-HIV PCP, resulting in a therapeutic delay resulting in high mortality. The most important factor to improve the mortality of non-HIV PCP is early diagnosis and starting of specific-PCP therapy as soon as possible.

Keywords: Community acquired pneumonia, Guidelines, Mortality, Non-HIV Pneumocystis pneumonia

\footnotetext{
*Correspondence: nobuhiro0204@hotmail.com

'Department of Pulmonology, Kameda Medical Center, 296-8602, 929

higashi-cho, Kamogawa-city, Chiba, Japan

Full list of author information is available at the end of the article
} 


\section{Background}

Pneumocystis pneumonia (PCP) not related to human immunodeficiency virus (HIV) can occur in immunosuppressed patients having malignancy or on immunosuppressive agents [1-10]. The mortality of patients with PCP without HIV infections ranges from 0 to $70 \%$ [1,3-10], compared to that of HIV-infected PCP patients, which ranges from 10 to $20 \%[1,4,9]$. Besides, mortality rates as high as $60-75 \%$ have been reported in PCP patients without AIDS who required mechanical ventilation $[11,12]$. The higher mortality among non-HIV PCP patients has been attributed to severe lung inflammation $[1,4,10]$, although the exact etiology accounting for these large differences in mortality has not yet been determined.

The A-DROP system proposed by the Japanese Respiratory Society (JRS), the CURB-65 score proposed by British Respiratory Society (BTS) and the Pneumonia Severity Index (PSI) proposed by the Infectious of Disease Society of America (IDSA) are widely used in classifying patients with community-acquired pneumonia (CAP) [13-15] in Japan. For the purpose of evaluating how correctly the conventional prognostic guidelines of CAP reflect the severity of non-HIV PCP, we retrospectively analyzed 21 patients with non-HIV PCP. It has never previously been reported that the severity of non-HIV PCP may be underestimated by these prognostic guidelines. This is the first report focusing on the limit of conventional prognostic guidelines of CAP for non-HIV PCP.

\section{Methods}

From the end of 2009 to the beginning of 2010 we retrospectively reviewed all the cases of PCP diagnosed as CAP in the Kameda Medical Center, Chiba, Japan. All the patients had undergone HIV testing and were negative. Patients with hospital associated pneumonia (HAP) were excluded. PCP was diagnosed based on polymerase chain reaction (PCR) and conventional PCP staining with Grocott methenamine silver stain or Diff-Quick ${ }^{\text {TM }}$ staining in respiratory samples such as induced sputum (IS) or bronchoalveolar lavage (BAL) fluid associated with radiographic infiltration on chest X-ray and computed tomography $(\mathrm{CT})$ findings on admission. All radiographic pictures showed infiltration confirmed by the pulmonologist and radiologist in our hospital. The decision to perform IS or BAL examination depended on the patient's general condition at the discretion of attending physicians. PCP diagnosis was based not solely on the positive PCR respiratory specimen but also on the clinical and radiological findings consistent with the diagnosis of PCP as well as complete recovery with anti-Pneumocystis jirovecii treatment alone. No biopsy was performed during this study. We compared the severity of 21 patients with PCP classified by A-DROP, CURB-65, and PSI, and analyzed the background and laboratory data of each.

\section{Statistical analysis}

Comparisons of group means were made by unpaired or paired $t$-tests or Mann-Whitney $U$-test. Contingency tables were evaluated by Fisher's exact probability test. $p$ values $<0.05$ were considered significant.

\section{Results}

\section{Patient characteristics}

The characteristics of the 21 patients with PCP are shown in Tables 1 and 2. The mean age was 71.5 years (range 57-88). Twelve patients (57.1\%) had rheumatic or autoimmune disease which was the most common underlying disease, followed by malignancy $(n=10,47.6 \%)$. Seventeen patients $(77.8 \%)$ were receiving steroid or immunosuppressants for the underlying disease. Prophylactic therapy consisting of trimethoprim-sulfamethoxazole (TMP/SMX) was used by only 1 patient (4.8\%).

\section{Treatment and outcomes}

All the patients received oral or parenteral (TMP/SMX and adjuvant steroid therapy. Eighteen (85.7\%) of the 21 patients had acute respiratory failure. Eight patients (38.1\%) in the study died.

\section{Severity of PCP by A-DROP}

The A-DROP scale was one of the prognostic guidelines for CAP proposed by JRS in 2005. It is a scoring system using age, degree of dehydration (serum blood urea nitrogen (BUN)), $\mathrm{SpO}_{2}<90 \%\left(\mathrm{PaO}_{2}<60 \mathrm{~mm} \mathrm{Hg}\right)$, orientation, and

\section{Table 1 Characteristics of PCP patients without HIV} infection $(\mathbf{n}=\mathbf{2 1})$

\begin{tabular}{lcc}
\hline Characteristics & Patients \\
\hline Sex & $\mathbf{n}$ & $\%$ \\
\hline Male & 11 & 52.4 \\
\hline Female & 10 & 47.6 \\
\hline Underlying disease & & \\
\hline Rheumatic and autoimmune diseases & 12 & 57.1 \\
\hline Malignancy & 10 & 47.6 \\
\hline Diabetes mellitus & 4 & 19.0 \\
\hline Chronic pulmonary diseases & 6 & 28.6 \\
\hline Heart diseases & 4 & 19.0 \\
\hline Cerebrovascular diseases & 2 & 9.5 \\
\hline Renal diseases & 2 & 9.5 \\
\hline Liver disease & 2 & 9.5 \\
\hline Long-term glucocorticoids alone & 4 & 19.0 \\
\hline Immunosuppressants alone /chemotherapeutic agents alone & 6 & 28.6 \\
\hline Long-term glucocorticoids combined & 7 & 33.3 \\
with chemotherapeutic/ & 1 & 4.8 \\
\hline immunosuppressive agents & & \\
\hline Table 1 legend - PCP, Pneumocystis pneumonia; SD, standard deviation. & \\
\hline
\end{tabular}


Table 2 Relationship between complications and outcome

\begin{tabular}{lccc}
\hline Complications & $\begin{array}{c}\text { Survivors } \\
(\mathbf{n}=\mathbf{1 3})\end{array}$ & $\begin{array}{c}\text { Non-survivors } \\
(\mathbf{n}=\mathbf{8})\end{array}$ & $\mathbf{p}$ \\
\hline Malignancy & 4 & 6 & 0.081 \\
\hline $\begin{array}{l}\text { Rheumatic and } \\
\text { autoimmune disease }\end{array}$ & 9 & 3 & 0.203 \\
\hline Diabetes Mellitus & 2 & 1 & 1.000 \\
\hline $\begin{array}{l}\text { Chronic pulmonary } \\
\text { disease }\end{array}$ & 3 & 3 & 0.631 \\
\hline Heart disease & 2 & 2 & 0.618 \\
\hline $\begin{array}{l}\text { Cerebrovascular } \\
\text { disease }\end{array}$ & 0 & 2 & 0.133 \\
\hline Renal disease & 1 & 1 & 1.000 \\
\hline Liver disease & 2 & 0 & 0.505 \\
\hline
\end{tabular}

Table 2 legend -Presented data are evaluated by Fisher's exact test.

systolic blood pressure. All our patients were classified by the A-DROP system. As a result, 18 patients (85.7\%) were classified as mild or moderate. Fifteen $(83.3 \%)$ of the 18 developed respiratory failure, and 7 (46.7\%) of the 15 died (Table 3).

\section{Severity of PCP by CURB-65}

CURB-65 is also a prognostic guideline for CAP, proposed by BTS in 1996. It seems to be similar to the A-DROP system, the greatest difference being the age value used in the scoring. While JRS defines males $>70$ years and females $>$ 75 years as high risk elderly, BTS classifies high risk elderly

Table 3 Distribution of patients and their mortality according to risk class

\begin{tabular}{rcccc}
\hline $\begin{array}{l}\text { Risk } \\
\text { groups }\end{array}$ & $\begin{array}{c}\text { Number of } \\
\text { patients (\%) }\end{array}$ & $\begin{array}{c}\text { Number of } \\
\text { patients with } \\
\text { respiratory } \\
\text { failure (\%) }\end{array}$ & $\begin{array}{c}\text { Mortality } \\
(\%)\end{array}$ \\
\hline A-DROP & 0 & $5(23.8)$ & $3(60)$ & $0(0)$ \\
\hline 1 & $6(28.6)$ & $5(83.3)$ & $2(33.3)$ \\
\hline 2 & $7(33.3)$ & $7(100)$ & $5(71.4)$ \\
\hline 3 & $2(9.5)$ & $2(100)$ & $1(50)$ \\
\hline $4 / 5$ & $1(4.8)$ & $1(100)$ & $0(0)$ \\
\hline 0 & $4(19)$ & $2(50)$ & $0(0)$ \\
\hline 1 & $3(14.3)$ & $2(66.7)$ & $0(0)$ \\
\hline 2 & $12(57.1)$ & $12(100)$ & $8(66.7)$ \\
\hline 3 & $0(0)$ & & $0(0)$ \\
\hline $4 / 5$ & $2(9.5)$ & $2(100)$ & \\
\hline CURB-65 & $0(0)$ & & $1(33.3)$ \\
\hline PSI & $4(19)$ & $2(50)$ & $6(50)$ \\
\hline III & $3(14.3)$ & $2(66.7)$ & $1(50)$ \\
\hline IV & $12(57.1)$ & $12(100)$ &
\end{tabular}

*In PSI, relations of risk classes to net points are as follows:

I: 0, II: 1-70, III: 71-90, IV: 91-130, V: >131.

Table 3 legend - PCP, Pneumocystis pneumonia; PSI, pulmonary severity index. age as $>65$ years for both sexes. In our study 19 patients (90.5\%) were classified as mild or moderate (class $0-2$ ); 16 of the 19 patients (84.2\%) developed acute respiratory failure, and 8 (42.1\%) of the 16 died (Table 3).

\section{Severity of PCP by PSI}

The PSI was proposed by the Infectious Diseases Society of America/American Thoracic Society (IDSA/ATS). It is considered to be more complicated and less convenient to use than the other scoring systems. It consists of 19 items such as age, underlying disease, gender, vital signs, etc. In our study, 14 patients $(66.7 \%)$ were classified as severe or extremely severe by PSI. All the 14 patients developed respiratory failure and 7 patients $(50 \%)$ died (Table 3).

\section{Distribution of patients and their mortality in each risk class of A-DROP, CURB-65 and PSI}

The majority of the PCP patients were categorized in risk classes $2-3$ by A-DROP and CURB-65, and III/IV by PSI. Of note are the very high patient mortalities in risk classes 2 by A-DROP and CURB-65, and class III/IV by PSI (Table 3 ).

\section{Comparison of the prognostic accuracy between A-DROP, CURB-65 and PSI}

The comparison of the prognostic accuracy of each guideline for CAP is shown in Table 4. It can be seen that the positive predictive values and negative predictive values for mortality in each system were low.

\section{Comparison of the characteristics between survivors and non survivors}

The lactate dehydrogenase (LDH) value tended to be higher and Alb/BUN tended to be lower in the non survivor group compared with the survival group, but this was not statistically significant. There were no significant differences in serum $\beta$-D-glucan ( $\beta$-DG), Krebs von den Lungen 6 (KL-6), body mass index (BMI) between the two groups. However, both the time between the initial visit and establishment of a diagnosis and the time between the initial visit and starting PCP therapy were significant much shorter in the survivor than non survivor group (Table 5).

\section{Discussion}

There are some widely used prognostic guidelines for CAP. These systems appear to be useful in assisting physicians to make more rational decisions regarding the need for admission [13-15]. Patient mortalities in the risk groups $3-5$ on A-DROP and CURB-65, and IV-V on PSI have previously been reported as $11.5-23.3 \%, 11.6-21.0 \%$ and $12.5-29.2 \%$, respectively [16-19]. A striking fact is that the majority of the PCP patients were categorized as mild 
Table 4 Comparison of the prognostic accuracy of the ADROP system and CURB-65 score and PSI

\begin{tabular}{cll}
\hline Sensitivity for mortality, $\%$ & & \\
\hline A-DROP scores & $3-5$ & 12.5 \\
\hline CURB-65 scores & $3-5$ & 0 \\
\hline PSI risk classes & IV- V & 87.5 \\
\hline Specificity for mortality, \% & \\
\hline A-DROP scores & $3-5$ & 84.6 \\
\hline CURB-65 scores & $3-5$ & 84.6 \\
\hline PSI risk classes & IV- V & 46.2 \\
\hline Positive predictive values for mortality, \% & & \\
\hline A-DROP scores & $3-5$ \\
\hline CURB-65 scores & $3-5$ \\
\hline PSI risk classes & IV- V & 0 \\
\hline Negative predictive values for mortality, \% & & 50 \\
\hline A-DROP scores & $3-5$ & 61.1 \\
\hline CURB-65 scores & $3-5$ \\
\hline PSI risk classes & IV- V \\
\hline
\end{tabular}

*In PSI, relations of risk classes to net points are as follows:

I: 0, II: 1-70, III: 71-90, IV: 91-130, V: >131.

Table 4 legend - PCP, Pneumocystis pneumonia; PSI, pulmonary severity index.

to moderate by these guidelines and resulted in respiratory failure, and poor outcomes. We emphasize that mortality prediction in PCP is not correct when these conventional guidelines for CAP are applied, even when PCP develops in the setting of CAP. Also, these guidelines definitely

Table 5 Patient characteristics on admission by prognostic outcome

\begin{tabular}{lccc}
\hline Item & $\begin{array}{c}\text { Survivors } \\
(\mathrm{n}=13)\end{array}$ & $\begin{array}{c}\text { Non-survivors } \\
(\mathrm{n}=8)\end{array}$ & $\mathrm{p}$ \\
\hline Age & $69.4(8.9)$ & $74.9(9.3)$ & 0.193 \\
\hline $\mathrm{BMl}\left(\mathrm{kg} / \mathrm{m}^{2}\right)$ & $22.3(3.5)$ & $22.5(1.7)$ & 0.872 \\
\hline$\beta-\mathrm{DG}(\mathrm{pg} / \mathrm{ml})$ & $93.8(161)$ & $82(64.2)$ & 0.846 \\
\hline $\mathrm{KL}-6(\mathrm{U} / \mathrm{ml})$ & $771(461)$ & $1588(1417)$ & 0.104 \\
\hline $\mathrm{LDH}(\mathrm{IU} / \mathrm{l})$ & $521(276)$ & $799(329)$ & 0.051 \\
\hline $\mathrm{CRP}(\mathrm{mg} / \mathrm{dl})$ & $8.22(4.35)$ & $9.62(4.92)$ & 0.502 \\
\hline Alb/BUN & $0.211(0.133)$ & $0.119(0.054)$ & 0.078 \\
\hline Lymphocytes $(/ \mu \mathrm{l})$ & $1203(1011)$ & $752(389)$ & 0.28 \\
\hline Neutrophils $/ / \mu \mathrm{l})$ & $7181(3012)$ & $7511(3083)$ & 0.825 \\
\hline WBC $(/ \mu \mathrm{l})$ & $9323(3581)$ & $8700(3103)$ & 0.7 \\
\hline Interval from admission to PCP diagnosis (days) & & \\
\hline & $4(2.83)$ & $7.88(3.56)$ & 0.012 \\
\hline
\end{tabular}

Interval from admission to start PCP-specific treatment (days)

$$
1.77(2.74)
$$

Results are means (SDs).

Table 5 legend - $\beta$-DG, $(1 \rightarrow 3)$ - $\beta$-D-glucan; BUN, blood urea nitrogen; BMI, body mass index; CAP, community-acquired pneumonia; CRP, C-reactive protein; KL-6, Krebs von den Lungen 6; LDH, lactate dehydrogenase; PCP, Pneumocystis pneumonia; PSI, pulmonary severity index; WBC, white blood cells. underestimate the severity of PCP as CAP. The important issue is why these guidelines cannot correctly estimate PCP severity. PCP without HIV infection shows quite different clinical pictures compared to PCP with HIV infection. PCP with HIV occurs slowly and gradually [20]. On the other hand, PCP without HIV is typically more acute and severe than when associated with AIDS [10], often resulting in acute respiratory failure requiring a need for mechanical ventilation. We suppose that this results from the differences of pathologic mechanisms between PCP with and without HIV. It is evident that PCP without HIV is an allergic reaction originating from Pneumocystis jirovecii. Pneumocystis elicits many kinds of immune responses, including those by lymphocytes, macrophages, neutrophils, dendritic cells, and epithelial cells $[1,21]$. There is now a considerable body of evidence showing that immune and inflammatory responses to Pneumocystis can have harmful as well as beneficial effects on host lungs.

Another reason why the mortality rate of PCP without HIV remains high is presumably that it is difficult to diagnose PCP according to nonspecific signs, symptoms and/or no reliable culture. Bollée et al. documented that the leading symptoms of PCP in HIV-uninfected cancer patients were fever (85.7\%), dyspnea (78.6\%), cough (57.1\%), and all three symptoms (44.6\%) on diagnosis [5], and $14.3 \%$ of the patients showed only one symptom. In our study, 4 out of 21 patients (19\%) were asymptomatic. In addition, $6 / 21$ patients (28.6\%) showed abnormality in chest X-ray on admission. It is possible that steroids and immunosuppressive drugs could mask fever and general fatigue on the initial visit. We strongly believe that clinicians are unable to diagnose non-HIV PCP by clinical picture or chest X-ray alone. The association with P. jirovecii cysts has been reported in HIV-uninfected PCP to be one tenth of that in HIV-PCP [4]. Therefore, the sensitivity of conventional staining methods for diagnosis of HIV-uninfected PCP is lower than that for PCP with HIV. Our study demonstrated the sensitivity of conventional staining to be $23.8 \%$. While Diff-Quik staining is highly sensitive, it requires considerable technical expertise [22]. It is likely that physicians are unable to diagnose PCP without HIV soon enough due to the reasons mentioned above.

A clue for making the early diagnosis of PCP is serum $\beta$-D-gulcan ( $\beta$-DG) and chest CT findings. Tasaka et al. reported the $\beta$-DG could be a serum indicator for the diagnosis of PCP with the cut-off value of $31 \mathrm{pg} / \mathrm{ml}$ $[23,24]$. In our study, the sensitivity of $\beta$-DG in diagnosing PCP was 10/21 (47.6\%) setting the cut-off value at $31 \mathrm{pg} / \mathrm{ml}$. We suggest that testing $\beta$-DG is effective for diagnosis of PCP. In testing, BAL is also well known to be more sensitive than IS, as many physicians previously reported [23,25]. In terms of a radiological approach, high resolution computed tomography (HRCT) should 
be performed if PCP is suspected. It is commonly known that chest CT shows ground glass appearance with a panlobular pattern or so-called crazy paving appearance in PCP patients [26,27]. These findings are also found in viral pneumonias, mycoplasmal pneumonia, alveolar hemorrhage, methotrexate pneumonia, and others. However, where the patient's background and characteristics are conducive, the presence of PCP should be suspected.

Conventional guidelines for CAP have recommended that clinical outcomes should be evaluated three days after initial therapy has been started [13,28-33]. In our study, 12 of the 13 (92.3\%) patients who received accurate anti-PCP therapy within 3 days from initial visit were cured. Ten of the $12(83.3 \%)$ patients received empiric therapy for PCP based on patient characteristics, laboratory data and radiological findings on HRCT. On the other hand, 7 of the $8(87.5 \%)$ patients who received anti-PCP therapy that was initiated after day 4 died. PCP without HIV tends to develop acute respiratory failure and results in a more severe, acute form of acute respiratory distress syndrome (ARDS) than PCP with HIV. Thus, only three days of doctor's delay in starting PCP therapy could be fatal as our study showed.

The limitation of our study is that it is a retrospective analysis in a very small population. Retrospective studies may be less reliable in terms of the data collected, particularly for data such as physical examination. A prospective study should be carried out and with more cases.

\section{Conclusions}

In conclusion, we suggest that conventional prognostic guidelines for CAP might underestimate the severity of HIV-uninfected PCP. Physicians should be aware of the possibility that PCP may occur in non-HIV patients having malignancy or rheumatic disease, receiving steroid and/or immunosuppressive therapy. The most important factor for improving the mortality of PCP without HIV could be the time when anti-PCP therapy is started.

\section{Competing interests}

The authors declare that they have no competing interests.

\section{Acknowledgements}

The authors are grateful for the diligent and thorough critical reading of their manuscript by Mr. John Wocher, Executive Vice President and Director, International Affairs/International Patient Services and Mr. Matthew Larew, Administrative Intern at Kameda Medical Center (Japan).

\footnotetext{
Author details

'Department of Pulmonology, Kameda Medical Center, 296-8602, 929 higashi-cho, Kamogawa-city, Chiba, Japan. ${ }^{2}$ Department of Rheumatology, Kameda Medical Center, 296-8602, 929 higashi-cho, Kamogawa-city, Chiba, Japan. ${ }^{3}$ Laboratory medicine, Kameda Medical Center, 296-8602, 929 higashi-cho, Kamogawa-city, Chiba, Japan.
}

Received: 29 August 2011 Accepted: 11 June 2012 Published: 11 June 2012

\section{References}

1. Thomas CF Jr, Limper AH: Pneumocystis pneumonia. N Engl J Med 2004 350:2487-2498.

2. Kovacs JA, Gill VJ, Meshnick S, Masur H: New insights into transmission, diagnosis, and drug treatment of Pneumocystis carinii pneumonia. JAMA 2001, 286:2450-2460.

3. Sepkowitz KA: Opportunistic infections in patients with and patients without Acquired Immunodeficiency Syndrome. Clin Infect Dis 2002, 34:1098-1107.

4. Limper AH, Offord KP, Smith TF, Martin WJ 2nd: Pneumocystis carinii pneumonia. Differences in lung parasite number and inflammation in patients with and without AIDS. Am Rev Respir Dis 1989, 140:1204-1209.

5. Bollée G, Sarfati C, Thiéry G, Bergeron A, de Miranda S, Menotti J, de Castro N, Tazi A, Schlemmer B, Azoulay E: Clinical picture of Pneumocystis jiroveci pneumonia in cancer patients. Chest 2007, 132:1305-1310.

6. Ward MM, Donald F: Pneumocystis carinii pneumonia in patients with connective tissue diseases: the role of hospital experience in diagnosis and mortality. Arthritis Rheum 1999, 42:780-789.

7. Komano Y, Harigai M, Koike R, Sugiyama H, Ogawa J, Saito K, Sekiguchi N, Inoo M, Onishi I, Ohashi H, Amamoto F, Miyata M, Ohtsubo H, Hiramatsu K, Iwamoto M, Minota S, Matsuoka N, Kageyama G, Imaizumi K, Tokuda H, Okochi Y, Kudo K, Tanaka Y, Takeuchi T, Miyasaka N: Pneumocystis jiroveci pneumonia in patients with rheumatoid arthritis treated with infliximab: a retrospective review and case-control study of 21 patients. Arthritis Rheum 2009, 61:305-312

8. Su YS, Lu JJ, Perng CL, Chang FY: Pneumocystis jirovecii pneumonia in patients with and without human immunodeficiency virus infection. J Microbiol Immunol Infect 2008, 41:478-482.

9. Overgaard UM, Helweg-Larsen J: Pneumocystis jiroveci pneumonia (PCP) in HIV-1-negative patients: a retrospective study 2002-2004. Scand J Infect Dis 2007, 39:589-595.

10. Yale SH, Limper AH: Pneumocystis carinii pneumonia in patients without acquired immunodeficiency syndrome: associated illness and prior corticosteroid therapy. Mayo Clin Proc 1996, 71:5-13.

11. Thomas CF Jr, Limper AH: Pneumocystis pneumonia: clinical presentation and diagnosis in patients with and without acquired immune deficiency syndrome. Semin Respir Infect 1998, 13:289-295.

12. Azoulay E, Thiéry G, Chevret S, Moreau D, Darmon M, Bergeron A, Yang K, Meignin V, Ciroldi M, Le Gall JR, Tazi A, Schlemmer B: The prognosis of acute respiratory failure in critically ill cancer patients. Medicine (Baltimore) 2004, 83:360-370.

13. The committee for the JRS guidelines in management of respiratory infections: The JRS Guidelines for the management of Community-acquired pneumonia in Adults, The Japanese Respiratory Society. Tokyo:; Updated 2007

14. Niederman MS, Mandell LA, Anzueto A, Bass JB, Broughton WA, Campbell GD, Dean N, File T, Fine MJ, Gross PA, Martinez F, Marrie TJ, Plouffe JF, Ramirez J, Sarosi GA, Torres A, Wilson R, Yu VL, American Thoracic Society: Guidelines for the management of adults with community-acquired pneumonia. Diagnosis, assessment of severity, antimicrobial therapy, and prevention. Am J Respir Crit Care Med 2001, 163:1730-1754.

15. British Thoracic Society Standards of Care Committee: BTS Guidelines for the Management of Community Acquired Pneumonia in Adults. Thorax 2001, 56(Suppl 4):IV1-IV64.

16. Shindo Y, Sato S, Maruyama E, Ohashi T, Ogawa M, Imaizumi K, Hasegawa Y: Comparison of severity scoring systems A-DROP and CURB-65 for community-acquired pneumonia. Respirology 2008, 13:731-735

17. Usui K, Tanaka Y, Noda H, Ishihara T: Comparison of three prediction rules for prognosis in community acquired pneumonia: Pneumonia Severity Index (PSI), CURB-65, and A-DROP. Nihon Kokyuki Gakkai Zasshi 2009, 47:781-785

18. Fine MJ, Auble TE, Yealy DM, Hanusa BH, Weissfeld LA, Singer DE, Coley CM, Marrie TJ, Kapoor WN: A prediction rule to identify low-risk patients with community-acquired pneumonia. N Engl J Med 1997, 336:243-250.

19. Chen JH, Chang SS, Liu JJ, Chan RC, Wu JY, Wang WC, Lee SH, Lee CC: Comparison of clinical characteristics and performance of pneumonia severity score and CURB-65 among younger adults, elderly and very old subjects. Thorax 2010, 65:971-977.

20. Pulvirenti J, Herrera P, Venkataraman P, Ahmed N: Pneumocystis carinii pneumonia in HIV-infected patients in the HAART era. AIDS Patients Care STDS 2003, 17:261-265. 
21. Walzer PD, Smulian AG: Pneumocystis species. In Mandell, Douglas, and Bennett's principles and practice of infectious diseases. Edited by Mandell GL, Bennett JE, Dolin R. Philadelphia: Churchill Livingstone/Elsevier; 2010:3377-3390.

22. Procop GW, Haddad S, Quinn J, Wilson ML, Henshaw NG, Reller LB, Artymyshyn RL, Katanik MT, Weinstein MP: Detection of Pneumocystis jiroveci in respiratory specimens by four staining methods. J Clin Microbiol 2004, 42:3333-3335.

23. Tasaka S, Hasegawa N, Kobayashi S, Yamada W, Nishimura T, Takeuchi T, Ishizaka A: Serum indicators for the diagnosis of Pneumocystis pneumonia. Chest 2007, 131:1173-1180.

24. Marty FM, Koo S, Bryar J, Baden LR: $(1 \rightarrow 3)$ beta-D-glucan assay positivity in patients with Pneumocystis (carinii) jiroveci pneumonia. Ann Intern Med 2007, 147:70-72.

25. Azoulay E, Bergeron A, Chevret S, Bele N, Schlemmer B, Menotti J: Polymerase chain reaction for diagnosing Pneumocystis pneumonia in non-HIV immunocompromised patients with pulmonary infiltrates. Chest 2009, 135:655-661

26. Tokuda H, Sakai F, Yamada H, Johkoh T, Imamura A, Dohi M, Hirakata M, Yamada T, Kamatani N, Kikuchi Y, Sugii S, Takeuchi T, Tateda K, Goto H: Clinical and radiological features of Pneumocystis pneumonia in patients with rheumatoid arthritis, in comparison with methotrexate pneumonitis and Pneumocystis pneumonia in acquired immunodeficiency syndrome: a multicenter study. Intern Med 2008, 47:915-923.

27. Kameda H, Tokuda H, Sakai F, Johkoh T, Mori S, Yoshida Y, Takayanagi N, Taki H, Hasegawa Y, Hatta K, Yamanaka H, Dohi M, Hashimoto S, Yamada H, Kawai S, Takeuchi T, Tateda K, Goto H: Clinical and radiological features of acute-onset diffuse interstitial lung diseases in patients with rheumatoid arthritis receiving treatment with biological agents: importance of Pneumocystis pneumonia in Japan revealed by a multicenter study. Intern Med 2011, 50:305-313.

28. Mandell LA, Bartlett JG, Dowell SF, File TM Jr, Musher DM, Whitney C, Infectious Diseases Society of America: Update of practice guidelines for the management of community-acquired pneumonia in immunocompetent adults. Clin Infect Dis 2003, 37:1405-1433.

29. Beam TR Jr, Gilbert DN, Kunin CM: General guidelines for the clinical evaluation of anti-infective drug products. Infectious Diseases Society of America and the Food and Drug Administration. Clin Infect Dis 1992, 15 (Suppl. 1):S5-S32.

30. Chow AW, Hall CB, Klein JO, Kammer RB, Meyer RD, Remington JS: Evaluation of new anti-infective drugs for the treatment of respiratory tract infections. Infectious Diseases Society of America and the Food and Drug Administration. Clin Infect Dis 1992, 15(Suppl. 1):S62-S88.

31. Niederman MS, Bass JB Jr, Campbell GD, Fein AM, Grossman RF, Mandell LA, Marrie TJ, Sarosi GA, Torres A, Yu VL: Guidelines for the initial management of adults with community-acquired pneumonia: diagnosis, assessment of severity, and initial antimicrobial therapy. American Thoracic Society. Medical Section of the American Lung Association. Am Rev Respir Dis 1993, 148:1418-1426.

32. British Thoracic Society: Guidelines for the management of communityacquired pneumonia in adults admitted to hospital. Br J Hosp Med 1993, 49:346-350.

33. Bartlett JG, Breiman RF, Mandell LA, File TM Jr: Community-acquired pneumonia in adults: guidelines for management. The Infectious Diseases Society of America. Clin Infect Dis 1998, 26:811-838.

doi:10.1186/2049-6958-7-2

Cite this article as: Asai et al:: Non-HIV Pneumocystis pneumonia: do conventional community-acquired pneumonia guidelines under estimate its severity?. Multidisciplinary Respiratory Medicine 2012 7:2.

\section{Submit your next manuscript to BioMed Central and take full advantage of:}

- Convenient online submission

- Thorough peer review

- No space constraints or color figure charges

- Immediate publication on acceptance

- Inclusion in PubMed, CAS, Scopus and Google Scholar

- Research which is freely available for redistribution

Submit your manuscript at www.biomedcentral.com/submit
Ciomed Central 